\title{
SOME OBSERVATIONS ON THE NESTING HABITS OF ADELAIDE'S WARBLER
}

By NINA G. SPAULDING

Adelaide's Warbler (Dendroica adelaidae Baird) is a species that is endemic to the island of Puerto Rico and the adjacent island of Vieques. It is a common resident at Algarrobo (between Manatí and Vega Baja) on the same five-hundred acre finca already described in my paper on the nesting habits of Latimer's Vireo. The dense jungle of icaco brush so prevalent over the finca is a favorite haunt of both species. However, their preferences differ in one respect; while Latimer's Vireo is to be found most frequently on the border of dense brush, Adelaide's Warbler favors almost impenetrable tangles. It is found in dense growth scattered over pasture land. It was also a visitor in the tangled scrub about the house that had purpously been left in its native state. It seemed undisturbed by the presence of man; all it asked to be a common visitor about the home was plenty of cover.

Song.-The song of this species is a clear, rather loud trill. It has several variations, as follows:

1. A rapid trill on one tone.

2. A rapid trill on one tone terminating with an upward inAlection.

3. A rapid trill on one tone terminating with a downward inflection.

4. A rapid downward trill.

5. A downward trill followed by an ascending trill.

6. A descending trill terminated by an emphatic upward inflected weé.

7. A rapid trill on the same tone with a marked retardation on the downward inflected notes at the end, thus : chch-

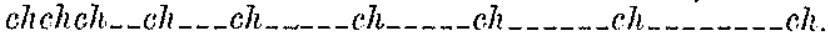

8. A song similar to that of the Nashville Warbler of North America.

9. The next song ean be best indicated by a downward trill, a $c h_{n_{-}} c h_{-\ldots} c h$, and an ascending wée.

10. An up trill and a down trill, terminated with an emphatic, upward inflected $h u-e ́$.

The frequency of the song of the male, during an hour's observation on the morning of February 10, 1931 was as follows: 10.29, $10.38,10.43,10.48,10.54,10.59,11.02,11.23,11.24,11.26,11.28$, 
$11.31,11.31 \frac{1}{2}, 11.31 \frac{3}{4}, 11.32$, an average of once every $41 / 4$ minutes, the longest time between songs, being 9 minutes and the shortest, being 15 seconds. On February 28, an Adelaide's Warbler was heard singing all the afternoon in a brushy pasture, south of the house.

My notes on the pre-nesting activities of this warbler are meager. Two were seen feeding together on March 9 in dense shrubs by an algarrobo tree. They uttered a weak chip as they searched rapidly among the leaves for insects, and sang occasionally. Again, on March 19, two were noted singing in close proximity. They answered one another. If they were a mated pair or two males, remains undetermined. It is possible that during courtship the female has a short period of singing. On March 24 a solitary male (sur)posedly) was noted singing and feeding. He dashed out in sight, after an insect. The snap of his bill was like that made by the breaking of tiny dried twigs. On April 8, 1931, two birds were answering each other, separated only by a trail. They appeared to fly off in opposite directions which would indicate that they were both males. Thereby, any foregone conclusions that these pairs seen flying about in the early spring, feeding and singing responsively, are mated pairs, is precluded, which leaves the problem as to any singing on the part of the female still unanswered. On April 11, 1930, from 9.30 to 10 , two birds were note singing responsively in a cocoanut grove. Also, on that date, a pair noted feeding together were not singing but were uttering the chip chip call note. As soon as one stopped, the other took it up. The latest record of responsive singing occurred on April 24, 1930. Two birds were singing in the bushes bordering the brook. One bird was in the dense shrubbery by the brook. The other was across a small open space in a ciump of bushes. They were singing the different variations of their characteristic trill. After one sang the other replied instantly, sometimes by the same trill given by the first and sometimes by a different one. Once, the bird in the bushes by the brook flew across the open space into the clump of brushes where the other bird was feeding. The other chased it back, through the open space to its original feeding place by the brook, where the responsive singing continued uninterruptedly. If they were of the same or opposite sexes remains undetermined.

Nesting Season.-We have a few records to help us to establish the length of the nesting season of this bird. Wetmore (Scientific Survey of Porto Rico and the Virgin Islands, vol. IX, 1927, pt. 4, 
p. 517) places the breeding season in May and June. The only records made up to 1921 are by Bowdish in 1900, Wetmore, 1912, and Suothers in 1921. Wetmore reports breeding activities on Vieques as early as the latter part of March. The next record was made in 1924 by Danforth (Journal of the Department of Agriculture of Porto Rico, X, 1926, p. 120). He reports finding a nest on May 6, and concludes that the birds apparently nest in May. However, there is evidence that breeding season extends over a longer period than those earlier records had led us to believe. Beatty (Journal of the Department of Agriculture of Puerto Rico, XV, 1931, p. 29) records an Adelaide's Warbler in the process of nest construction an early as April 14. On the 27th in the same month he located an incubating bird. More extended observations place the beginnings of nesting activities at a still earlier date. As early as April 9, (1931), I noted a pair of these warblers feeding juveniles that were evidently just out of the nest. They were also observed on the 11th, 12th and 24th. From this data we may conclude that the nest building season may begin at quite an early date in March. According o Wetmore's observations on Vieques, it would seem that the nesting period covers practically the same length of time on the two islands.

Nest.-Nests of this warbler proved exceedingly difficult to find. This was due to three reasons: their singing habits are such that they are of no aid at all in locating a nest; their nests are placed in such impenetrable, brushy tangles that one does not naturally walk in those places; they are so well concealed that if one passed a nest, the chances are that he would not see it. In view of these facts, I feel myself fortunate to have located even one during the three winters spent on the finca. That eventful occasion happened on the afternoon of May 7, 1930, and was probably due to the fact that the bird had inadvertently placed its nest not far from a trail, where there was a slight opening into the brush. A bulgy appearance among a thick cluster of leaves, near the top of an icaco shoot, about ten feet in height, aroused suspicion. Upon nearer approach, it proved to be the long-sought nest of this species. It contained an incubating bird, and was so well screened from view, that after completely encircling it, only one place was found sufficiently exposed for observation. There, between the leaves, the tail and back of an incubating bird could be indistinctly seen.

This nest was situated in the tallest of the surrounding icaco saplings. It leaned at an angle of about 45 degrees. Iis terminal 
fork consisted of a bunch of three or four upright twigs, heavily foliaged. It was in the midst of these that the bird had placed her nest. These twig's gave ample support, sustaining the nest in an upright position above the main stem, and the heavy foliage almost entirely concealed it. It was about 8 feet above the ground. The nest was a closely woven, cup-shaped affair, and was composed of soft grass densely interwoven except on the outside at the base, where it was rather loose and dangling, and was composed of the coarser seed-stallss of grasses that were soft and tattered, being partially dessicated. It was lined with feathers.

Ornithological literature yields meager and varying reports on the nest of this species. Referring to the publications already mentioned, we find the following, which for comparison I have arranged as follows :

\begin{tabular}{|c|c|c|c|}
\hline Authority & Elevation & Main Composition & Lining \\
\hline Wetmore & $4 \mathrm{ft}$. & gray moss & fine grass \\
\hline Danforth & $3 \mathrm{ft}$. & soft grass & none \\
\hline $\begin{array}{l}\text { Beatty } \\
\text { nests) }\end{array}$ & $6 \mathrm{ft}$ & soft grass & $\begin{array}{l}\text { feathers and } \\
\text { hair }\end{array}$ \\
\hline The writer & $8 \mathrm{ft}$ & soft grass & feathers \\
\hline
\end{tabular}

Note the close agreement of Beatty's and the writer's reports. In the case of one of Beatty's nests, however, he found some cotton added to the feathers. In regard to Danforth's nest, as he says it was unoccupied may I venture to suggest that it was unfinished. The description of Wetmore's nest, which was also an unoccupied one suggests that of a Latimer's Vireo, except that no mention is made of the Tillandsia stems always used as the main composition in nests of this species. In view of reports on nests that were actually occupied, a question is raised, not satisfactorily answered, as to the employment of moss in the nest of this species.

Nest measurements were as follows:

$$
\begin{gathered}
\text { Diameter }\left\{\begin{array}{l}
\text { Inside } 13 / 4^{\prime \prime} \times 11 / 2 \\
\text { Outside } 21 / 2^{\prime \prime} \times 21 / 4
\end{array}\right. \\
\text { Depth }\left\{\begin{array}{l}
\text { Outside } 21 / 4^{\prime \prime} \\
\text { Inside } 1 \frac{1}{2 \prime \prime}
\end{array}\right.
\end{gathered}
$$


Eggs.-The eluteh observed consisted of 3 eggs. They were white sprinkled with small dots of reddish brown. A wreath of heavy splashes of the same color encircled the larger end. One egg measured as follows: $141 / 2 \mathrm{~mm} \times 11 \mathrm{~mm}$. Only the one was measured due to fear of desertion on the part of the incubating bird.

Incubation.-This activity was allotted to the female, a conclusion reached because of the fact that the setting bird did not sing. When found on May 7, the eggs were within 11 days of hatching. During the first four clays the approach to the nest was accomplished by alighting directly on the nest rim. On the 5 th day, at 4.49 P.M., the bird came sueaking up the twigs behind the leaves, and stealthily crept into the nest from the farther side. From that time, this was her usual method of approach. When departing from the nest she usually dropped down into the bushes, but sometimes flew directly into the brush beyond. On May 15, when the eggs were within 3 days of hatching she showed greater caution on leaving the nest, by looking in every direction before flying or sliping down into the bushes. Until this day, she had liept herself absolutely invisible when away from the nest, but on the morning of the 15th at 10.04, when ready to leave it she spread her wings when in a sitting position and slowly crept out, behind some leaves, then down the branch about a foot, where she stood for a few seconds. She captured an insect, then keenly inspected the leaves for more, after which, she crept back up the twig and into the nest. The time out was 2 minutes. Later, at 11, she flew out of the nest and out of sight but in 1 minute was visible on a twig below it. She pecked at a leaf once or twice. In 3 minutes she was back in the nest, and again, on the some day, when she was off for 26 minutes, she was within sight of and not far from the nest during the last four minutes of her absence.

As to restlessness, her behavior on the nest varied. On May 11, she sat quietly in the morning until noon, when she began to show distress from the heat of the broiling noonday sum, by sitting with her bill open. The sun's rays fell between the icaco leaves directly upon her. At 12.32, she was sitting protractedly with bill open. At 12.38, she raised herself above the nest, and spread her wings, as if either for relief from the heat, or to cool the eggs. After 3 minutes, she preened, spreading on wing, then sat with bill wide open. 5 minutes later, she raised herself as if to admit air, and in 3 minutes, changed her position so that she was sitting with her side toward me instead of her tail. This position was maintained 
for 7 minutes, when she changed again to her usual position, with tail toward me. Observations ceased at 12.57. On the 14th and 15th, when observations were resumed she was normally quiet. However, on the $16 \mathrm{th}$, she became exceedingly restless. She was constantly rising, then settling, tucking her head under her breast, stretching her head over the rim of the nest and looking all around. The temperature that day was 99 degrees in the shade.

The following morning, May 17, the extreme nervousness of the bird noted on the 16th was lacking. She was incubating on my arrival and remained thus for 36 minutes sitting very quietly.

She was still feeling the effect of the heat, for her bill was open upon my approach and she at once arose and remained standing during 4 minutes. She turned the eggs 3 times during the morning. This was the day preceeding the hatching of the eggs.

The length of the incubating periods varied from 20 minutes to 36 minutes. The average for one period was 26 minutes. 14 hours 27 minutes was the total time spent in observation during incubation. The female incubated a total of 7 hours 12 minutes or about half of the total time of observation.

The male proved himself an adept at complete concealment during this time. Not once was even a glimpse of him obtained. $\mathrm{He}$ sang, but chiefly over in the brushy tract that lay across the trail from the nest. Occasionally, however, he was heard in bushes adjacent to the nest, but he was such a wanderer and his songs were so infrequent that one could never locate his nest, by following his voice.

Rearing of the Young.-The eggs hatched on May 18, 11 days after the nest was found. Both parents shared in the care of the offspring. The similarity in the plumage precludes any definite statement in regard to the first appearance of the male at the nest. On May 19, the day after hatching, at 3.55 P. M., the first positive knowledge was obtained on that score when both birds appeared at the same time, and one of them sang, thus proving himself to be the male. At 4.02, one of the pair fed and brooded. At 4.06, the male sang, proving that it was the female who was on the nest. When she heard him, she perked up her head and slipped off. At 4.10 , both birds again arrived at the nest. One of them fed the young, and then the other crept inside and brooded. At 4.17, the brooding bird flew and the young were left uncovered. The nest was vacated by the parents for 24 minutes, though one feeding occurred during that time. At 4.41 , the pair again arrived at the nest 
togeiher one feeding and the other brooding as before. No singing was noted while this bird was on the nest. I concluded that the brooding bird was the male and that he shared in the brooding as well as in the feeding.

Excrement was eaten 5 times from 9.30 to 11.50 in the morning: and twice from 2.30 tc 5.32 , in the afternoon. During that time, there were 17 periods of brooding, the longest lasting 17 minutes, and the shortest, 3 minutes. The average length of a brooding pe. riod was 8 minutes, 45 seconds. The longest time the young were left uncovered was 29 minutes; the shortest, 4 minutes, the average being 13 minutes 22 seconds. Feedings averaged every 17 minutes 53 seconds.

On the following day, May 20, observations were made from 9.25 to 12. Not once did both of the birds arrive at the nest at the same time. At 11.46, when the brooding bird flew, the mate instantly arrived at the nest with insects, proving that both birds were working. There were 6 periods of brooding, during 3 of which, there was no singing on the part of the bird off the nest, possibly indicating that the brooding bird was the male though it was not positive proof. The length of the 6 brooding periods in minutes was $3,15,13,15,9$ and 6 , respectively. The periods when the female was known to be brooding because the male was heard singing, were longer than when no singing was heard, being the periods that were 15, 13 and 15 minutes in duration. Brooding periods averaged 10 minutes 10 seconds as compared with 8 minutes 45 seconds on the previous day. The longest time that the young were left uncovered was 25 minutes and the shortest 7 minutes, as compared with 29 minutes and 4 minutes on the previous day. The average time uncovered was 15 minutes 40 seconds. Feeding occurred 18 times averaging every $811 / 18$ minutes as compared with every 17 minutes 15 seconds on the previous day. Times between fedings in minutes were 4, 2, 4, $5,2,3,2,3,22,16,35,2,7,15,9,4,5$ and 9 respectively. The longest were during the brooding periods, when the young were never fed, with the exception of one occasion, subsequently noted.

Excrement was eaten by the bird before entering to brood. At 10.07, for the first time a sac was carried out of the nest into the bushes, and dropped. The male averaged a song every $91 / 2$ minutes. Two periods of unusual frequency occurred, the first lasting from 10.45 to 11.01 . He sang 35 times, averaging a song every 7 seconds. The second period began at 11.46 and ceased at 11.54, when one of the pair began to brood. No more singing occurred while the brood- 
ing was in progress. The insects fed were larger than on the first dy, most loads being visible as they protruded from the bird's bill.

On May 21, the third day, two changes in behavior on the part of the parents were noted. The minute the brooding bird flew the mate took her place, and once the mate brought the brooding bird an insect, who in turn fed it to the young. When a camera was set up, the brooding bird remained tenaciously on the nest until it was directly in front of and very close to her, when she flew. It was a long time before either of the pair returned. Scolding notes and an occasional song could be heard, until finally, one ventured up the branch below the nest, but was too frightened to enter. After a few minutes another attempt was made with the same result. The third attempt was successful. One of the pair crept up the branch to the nest rim and fed the hungry young. Insects were then brought 4 times in quick succession. The click of the camera was unheeded by the busy pair.

It will be noted that these warblers offered no resistance when the nest was approached. However, in time of extreme danger they became ardent defenders of their offspring, even to risking their own lives. It was not by direct attack, but by behaving in such a manner as to attract attention to hemselves, and thus away from the young. An exhibition of this sort occurred the first day the young were out of the eggs. The owner of the finca inadvertently passed directly in front of the nest when mounted on his horse. He did not see it, but his eye was at once attracted to something fluttering in the grass at his horse's feet, which he soon made out to be a bird. Then he saw the nest and that it contained young birds. The parent had made as big a commotion as a small bird could, to draw attention away from her newly hatched young.

On May 21, it was noted that the excrement sacs were both eaten and carried away by the parents.

An examination of the young, when 6 days old disclosed a row of black pin feathers tipped with white extending down the spine. Similar ones were also visible through the down on the head. On the sides, directly below the wings was a row of yellow pin feathers. The wings were bare. The bill as dark gray edged with white. Legs and feet were gray. Unfortunately observations during the remaining days of the nesting cycle were prevented by the necessity of other duties which prevented the author from continuing her observations. 


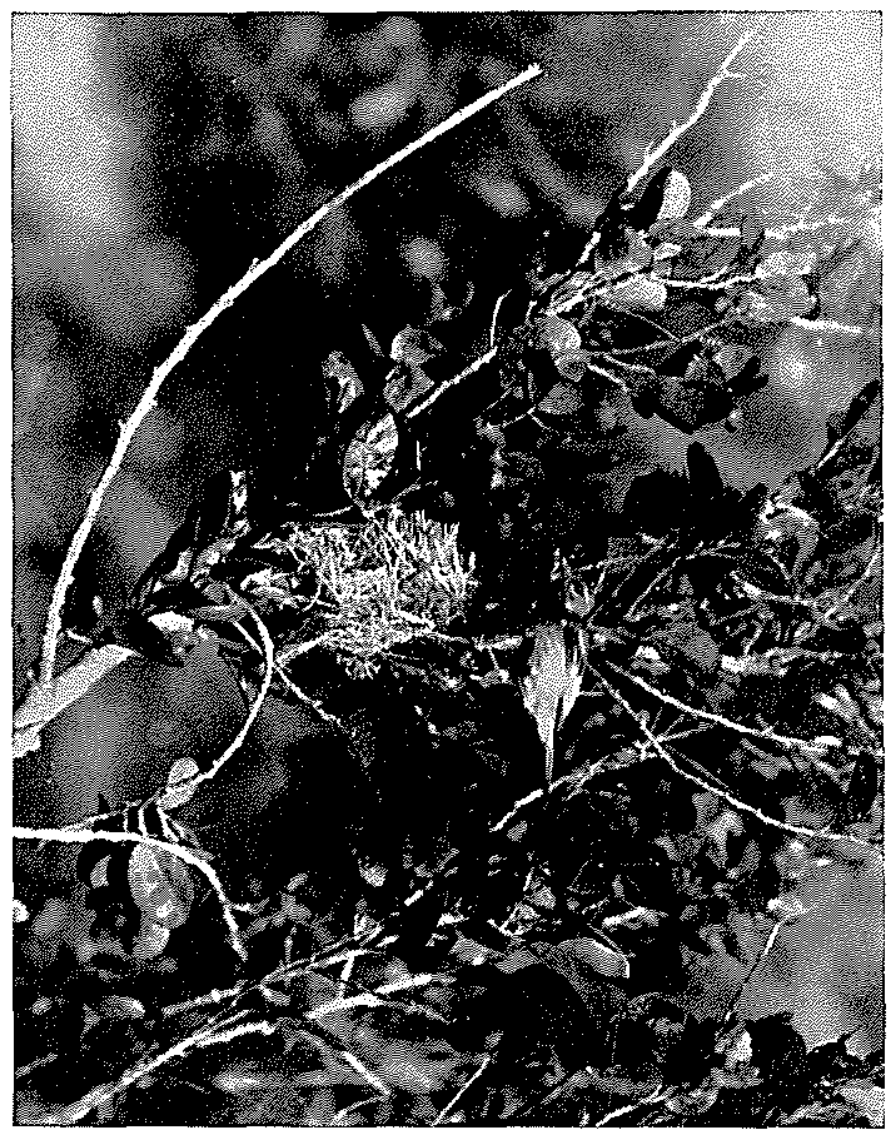

